\title{
Leishmaniose visceral e hepatite infecciosa em cachorro-vinagre mantido em cativeiro no Brasil - Relato de Caso
}

\section{Visceral leishmaniasis and infectious hepatitis in bush dog from captivity in Brazil - Report of case}

\author{
Arleana do Bom Parto Ferreira de Almeida ${ }^{1 *}$; Daphine Ariadne Jesus de Paula ${ }^{1}$; \\ Edson Moleta Colodel'; ${ }^{2}$ Valéria Dutra ${ }^{2}$; \\ Luciano Nakazato²; Valéria Régia Franco Sousa ${ }^{2}$
}

\section{Resumo}

Dentre os mamíferos, os canídeos são os mais frequentemente infectados por Leishmania sp. O presente artigo relata a ocorrência de Leishmania (Leishmania) infantum chagasi e inclusões intranucleares sugestivas de adenovírus canino 1, em cachorro vinagre (Speothos venaticus) mantido no zoológico da Universidade Federal de Mato Grosso, Cuiabá, Mato Grosso. O relato demonstra a importância dos canídeos silvestres como reservatórios de agentes de importância veterinária e de saúde pública, reforçando a necessidade de estudos com esses animais acerca de seus hábitos, comportamento e manejo sanitário.

Palavras-chave: Cachorro-vinagre, leishmaniose visceral, hepatite infecciosa

\begin{abstract}
Among mammals, the canids are most often infected by Leishmania sp. This paper reports the occurrence of Leishmania (Leishmania) infantum chagasi as well as the presence of intranuclear inclusions resembling viral particles of canine adenovirus-1 in a bush dog (Speothos venaticus) kept in captivity at the zoo of Federal University of Mato Grosso, central area of Brazil. The report demonstrates the importance of wild canids as reservoirs of agents of veterinary and public health importance, and it emphasizes the necessity of further studies with these animals concerning their habits, behavior and sanitary management.
\end{abstract}

Key words: Bush dog, visceral leishmaniasis, infectious hepatitis

\footnotetext{
Pós-graduandas do Programa de Pós-graduação em Ciências Veterinárias. Departamento de Clínica Médica Veterinária; Universidade Federal de Mato Grosso, UFMT. E-mail: arleferreira@gmail.com; daphine.depaula@gmail.com

2 Professores Doutores do Departamento de Clínica Médica Veterinária, Universidade Federal de Mato Grosso, UFMT. E-mail: moleta@ufmt.br; valdutra@ufmt.br; lucnak@ufmt.br; regia@ufmt.br

* Autor para correspondência
} 


\section{Introdução}

Leishmaniose visceral (LV) é uma zoonose de caráter progressivo, sistêmico e frequentemente fatal, causado nas Américas pelo protozoário Leishmania (Leishmania) infantum chagasi. Anualmente, cerca de 500.000 pessoas são infectadas por este parasito, sendo o maior número de casos registrados em Bangladesh, Índia, Nepal e Brasil (WHO, 2008). Tais agentes possuem, como vetores no Brasil, flebotomíneos das espécies Lutzomyia longipalpis e L. cruzi (PALATNIK-DE-SOUSA et al., 2001).

Diversas espécies de mamíferos podem se infectar por Leishmania sp. No entanto, os canídeos são os mais frequentemente relatados com a infecção (PALATNIK-DE-SOUSA et al., 2001). Os canídeos silvestres comumente servem como reservatórios do parasito. Entretanto, a possibilidade de transmissão para o homem ainda é discutida. Dentre aqueles relatados com infecção encontra-se cachorro-do-mato (Cerdocyon thous), raposa do campo (Lycalopex vetulus) (CURI; MIRANDA; TALAMONI, 2006), cachorro-vinagre (Speothos venaticus) (FIGUEIREDO et al., 2008). Contudo, somente Cerdocyon thous é considerado reservatório da LV no Brasil (COURTENAY et al., 1996).

A hepatite infecciosa canina (HIC) é uma doença viral de espécies domésticas e selvagens das famílias Canidae e Ursidae causada por adenovírus canino 1 (CAV-1). A morte pode ocorrer de forma superaguda ou aguda (INKELMANN et al., 2007). Há descrições da infecção em outros canídeos (GESE et al., 2004; ZARNKE; VER HOEF; DELONG, 2004), mas nenhum relato em cachorro-vinagre.

Descreve-se, no presente relato, a detecção de Leishmania (Leishmania) infantum chagasi e inclusões intranucleares sugestivas de adenovírus canino 1 (CAV-1) em cachorro vinagre mantido em cativeiro no zoológico da Universidade Federal de Mato Grosso, Cuiabá, Brasil através da técnica de PCR-RFLP e análise histopatológica.

\section{Relato de Caso}

Cachorro vinagre (Speothos venaticus), fêmea, dois anos, oriundo do Zoológico da Universidade Federal de Mato Grosso, Cuiabá, com histórico de morte após anestesia com tiletamina-zolazepam $5 \mathrm{mg} / \mathrm{kg}$ pela via intramuscular durante manejo para coleta de amostras visando realização de exames laboratoriais, foi encaminhado refrigerado ao setor de Patologia Veterinária do HOVET-UFMT no dia 16 de março de 2008, para realização de necropsia.

Durante a necropsia foram coletados fragmentos de pele, linfonodo, fígado, pulmão, rim e coração, conservados em formol a $10 \%$, para análise histológica e imuno-histoquímica (IHQ), além de fragmentos de pele, medula óssea, linfonodo, baço, fígado, rim e SNC que foram armazenados em microtubos previamente identificados e conservados a $-20^{\circ} \mathrm{C}$ para análise molecular pela técnica de reação em cadeia pela polimerase (PCR) para detecção de DNA de Leishmania sp.

Para técnica IHQ seguiu-se protocolo de Ikeda et al. (2007) usando-se secções incluídas em parafina de fígado, pulmão, pele, medula óssea. O KIT LSAB (K0690, Dako Corporation, Carpinteria, Califórnia, EUA) foi utilizado como sistema de detecção imuno-histoquímica. As amostras foram incubadas overnight com anticorpo primário policlonal antiLeishmania produzido pelo Departamento de Patologia da Escola de Medicina da Universidade de São Paulo, São Paulo - SP.

A extração de DNA foi realizada de acordo com Almeida (2009) pela técnica de fenol-clorofórmio e a PCR foi processada utilizando os primers 150 (sense) 5'-GGG(G/T)AGGGGCGTTCT(C/G) CGAA-3' e 152 (antisense) 5' (C/G)(C/G)(C/G) (A/T)CTAT(A/T)TTACACCAACCCC-3' que amplifica uma fragmento de DNA de $120 \mathrm{pb}$ de todas as espécies de Leishmania, e o produto de amplificação fracionado por eletroforese em gel de agarose 2,0\% corado com brometo de etídeo. Para a caracterização das espécies de Leishmania envolvidas utilizou-se a técnica de PCR-RFLP 
mkDNA (ALMEIDA, 2009). Sucintamente, $5 \mu 1$ do produto da amplificação foram digeridos por $1 \mathrm{U}$ da enzima HaeIII e incubados por 3 horas a $37^{\circ} \mathrm{C}$. Fragmentos de restrição foram separados em gel de poliacrilamida a $10 \%$, corados com brometo de etídeo e comparados com as cepas padrão de Leishmania (Leishmania) chagasi (MHOM/BR/74/ PP75) e Leishmania (Viannia) braziliensis (MHOM/ BR/75/M2903), provenientes do Instituto Oswaldo Cruz/FIOCRUZ, Rio de Janeiro.

Macroscopicamente, o fígado estava aumentado em volume, finamente irregular na superfície capsular, com coloração vermelho escuro, e com pontilhado claro na superfície capsular e de corte. Microscopicamente, no fígado, havia hepatite necrótica e linfoplasmocitária com presença ocasional de corpúsculos de inclusão intranucleares anfofílicos (Figura 1). Estes achados morfológicos são compatíveis com aqueles descritos em casos de hepatite infecciosa canina (INKELMANN et al., 2007). No fígado, adicionalmente havia infiltrado periacinar granulomatoso com macrófagos contendo estruturas intracitoplasmáticas morfologicamente similares a amastigostas de Leishmania sp. Reação inflamatória granulomatosa também foi observada na pele, linfonodos subcutâneos, pulmão, medula óssea e baço. Amastigotas de Leishmania sp. foram evidenciadas, frequentemente relacionadas com lesões granulomatosas nos tecidos através da técnica de imuno-histoquímica.

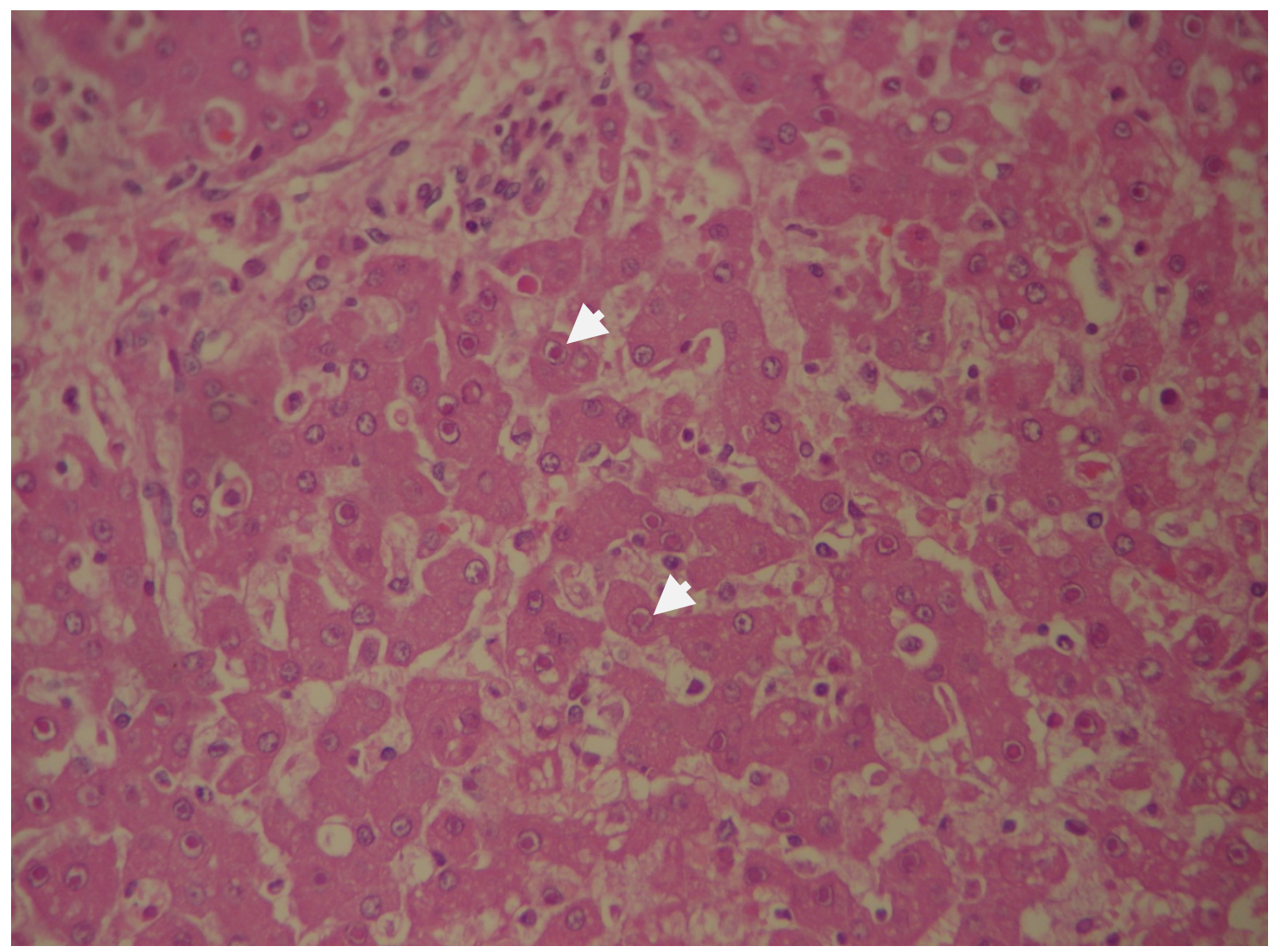

Figura 1. Aspecto histológico do fígado de Speothos venaticus mostrando hepatócitos com núcleos aumentados, vesiculosos, com cromatina marginada contendo corpúsculos de inclusão eosinofílicos circundados por alo claro (seta). HE. 100x 
Na técnica de PCR houve amplificação de DNA de Leishmania sp. nas amostras de pele, medula óssea, rim, baço, linfonodo, sistema nervoso central e fígado, sendo através do método de PCR-RFLP caracterizada a espécie envolvida como sendo $L$. (L.) i. chagasi.

\section{Discussão}

No Brasil foram relatados dois casos de infecção por $L$. (L.) i. chagasi em cachorro vinagre, sendo ambos mantidos em cativeiros em áreas endêmicas para LV (FIGUEIREDO et al., 2008; LUPPI et al., 2008). Em relato ocorrido na cidade do Rio de Janeiro, o estado de origem do animal era o mesmo do presente relato, ressaltando possível disseminação do agente entre os zoológicos do país (FIGUEIREDO et al., 2008).

Para Figueiredo et al. (2008) o estudo da ocorrência de infecção por Leishmanias nestes animais reforça a importância dos mesmos no ciclo de transmissão em ambiente silvestre e do próprio cativeiro. Para os mesmos autores o estudo parasitológico e/ou sorológico desses animais e de outros canídeos silvestres, que em algumas áreas endêmicas chegam a apresentar soroprevalência de 16,12 a 60\% (SOBRINO et al., 2008), ajudam a controlar a disseminação dessa zoonose tendo em vista a ocorrência de casos assintomáticos (CURI; MIRANDA; TALAMONI, 2006) como no animal relatado.

A observação de inclusões anfofílicas características da infecção pelo adenovírus canino - 1 , agente causador da hepatite infecciosa, que pode se apresentar na forma superaguda ou aguda (INKELMANN et al., 2007), sugere a associação desta afecção no desfecho clínico do cachorro vinagre relatado.

\section{Conclusão}

$\mathrm{O}$ encontro de cachorro-vinagre co-infectado com leishmaniose visceral e hepatite infecciosa demonstra a importância dos canídeos silvestres como reservatórios de agentes de importância veterinária e de saúde pública, reforçando a necessidade de estudos com esses animais acerca de seus hábitos, comportamento e manejo sanitário.

\section{Referências}

ALMEIDA, A. B. P. F. Inquérito soroepidemiológico e Caracterização da leishmaniose canina por PCR-RFLP em Cuiabá, Mato Grosso. 2009. Dissertação (Mestrado em Ciências Veterinárias) - Universidade Federal de Mato Grosso. Cuiabá, Mato Grosso.

COURTENAY, O.; SANTANA, E. W.; JOHNSON, P. J.; VASCONCELOS, I. A. B.; VASCONCELOS, A. W. Visceral leishmaniasis in the hoary zorro Dusicyon vetulus: a case of mistaken identity. Transactions of the Royal Society of Tropical Medicine and Hygiene, London, v. 90, p. 498-502, 1996.

CURI, N. H. A.; MIRANDA, I.; TALAMONI, S. A. Serologic evidence of Leishmania infection in freeranging wild and domestic canids around a Brazilian National Park. Memórias Instituto Oswaldo Cruz, Rio de Janeiro, v. 101, p. 99-101, 2006.

FIGUEIREDO, F. B.; GREMIÃO, I. D. F.; PEREIRA, S. A.; FEDULO, L. P.; MENEZES, R. C.; BALTHAZAR, D. A.; SCHUBACH, T. M. P.; MADEIRA, M. F. First report of natural infection of a bush dog (Speothos venaticus) with Leishmania (Leishmania) chagasi in Brazil. Transactions of the Royal Society of Tropical Medicine and Hygiene, London, v. 102, p. 200-201, 2008.

GESE, E. M.; KARKI, S. M.; KLAVETTER, M. L.; SCHAUSTER, E. R.; KITCHEN, A. M. K. Serologic Survey for Canine Infectious Diseases among Sympatric Swift Foxes (Vulpes velox) and Coyotes (Canis latrans) in Southeastern Colorado. Journal of Wildlife Diseases, United States, v. 40, n. 4, p. 741-748, 2004.

IKEDA, F.A.; LAURENTI, M. D.; CORBETT, C. E.; FEITOSA, M. M.; MACHADO, G. F.; PERRI, S. H. V. Histological and immunohistochemical study of the central nervous system of dogs naturally infected by Leishmania (Leishmania) chagasi. Brazilian Journal of Veterinary Research and Animal Science, São Paulo, v. 44, p. 5-11, 2007. 
INKELMANN, M. A.; ROZZA, D. B.; FIGHERA, R. A.; KOMMERS, G. D.; GRAÇA, D. L.; IRIGIYEN, L. F.; BARROS, C. S. L. Hepatite infecciosa canina: 62 casos. Pesquisa Veterinária Brasileira, Rio de Janeiro, v. 27, n. 8, p. 325-332, 2007.

LUPPI, M. M.; MALTA, M. C. C.; SILVA, T. M. A.; SILVA, F. L.; MOTTA, R. O. C.; MIRANDA, I.; ECCO, R.; SANTOS, R. L. Visceral leishmaniasis in captive wild canids in Brazil. Veterinary Parasitology, Amsterdan, v. 155, p. 146-151, 2008.

PALATNIK-DE-SOUSA, C. B.; SANTOS, W. R.; FRANÇA-SILVA, J. C.; COSTA, R T.; REIS, A. B.; PALATNIK, M.; MAYRINK, W.; GENARO, O. Impact of canine control on the epidemiology of canine and human visceral leishmaniasis in Brazil. American Journal Tropical Medicine and Hygiene, Baltimore, v. 65, n. 5, p. 510-517, 2001.
SOBRINO, R.; FERROGLIO, E.; OLEAGA, A.; ROMANO, A.; MILLAN, J.; REVILLA, M.; ARNAL, M.C.; TRISCIUOGLIO, A.; GORTÁZAR, C. Characterization of widespread canine leishmaniasis among wild carnivores from Spain. Veterinary Parasitology, Amsterdan, v. 155, p. 198-203, 2008.

WORLD HEALTH ORGANIZATION - WHO. 2008. Disponível em: <http://www.who.int/leishmaniasis/ disease_epidemiology/en/index.html $>$. Acesso em: 21 nov. 2008.

ZARNKE, R. L.; VER HOEF, J. M.; DELONG. R. A. Serologic survey for selected disease agents in Wolves (Canis lupus) from Alaska and the Yukon territory, 19842000. Journal of Wildlife Diseases, United States, v. 40, n. 4, p. 632-638, 2004. 
